Tongue beginning to moisten. Bowels still constipated. Area of splenic dulness much increased. No tenderness to pressure in any part of body.

November 1st. Chills continue. Appetite is gone, and tongue becoming dry and glazed again. Is in an indifferent state most of the time, but at times will appear quite interested in how he is getting along. Pulse does not come below 72, but temperature reaches normal nearly every day.

November 8th. Bowels moved eight times to day - the first time has had any looseness; otherwise condition the same.

November 20th. Bowels regular every second day since the 8 th. Mouth and throat sore and very dry, making it difficult for him to talk. Five hours after, chill, pulse only 74 and quite full, but short and easily compressed. Sordes have been forming on teeth past fow days. Jaundiced to-day for the first time. Iiver dulness has been increasing in area since 8 th.

November 24th. Has vomited occasionally since the 20th. At 2 P. M., pulse 100 ; no temperature. Talking in a rambling way, and complains of being unable to see at times. Continued this way until 4.30 P. M., when stopped talking, and died in about one minute without any struggle. Had no discharge from urethra for three weeks before he died.

Autopsy, fifteen hours' after death. Emaciation not extreme. Rigor mortis present. When sternum was removed, and organs viewed in situ, the heart seemed to be crowded up from below, and was not covered anteriorly by lung, but lay in plain view. Other organs appeared normal in position. The pleural and pericardial sacs contained about three times normal amount of fluid. Heart, more than one-half larger than normal; shape natural; color dark and veins of heart substance much distended with blood. Lungs, outside of hypostatic congestion at backs, nothing to note. Liver, size double ; shape, normal ; color dark, and consistency less firo than normal. Gall-bladder contained one-quarter of a pint of gall, the duct being plugged with mucus. Stomach, size about normal, and contained one pint of dirty-greenish fluid. Kidneys, left, seven inches long and right, six ; very light color when opened; shape normal, except the lower anterior part of left, which had a bunch size of walnut; this bunch was of the same consistency, and to naked eye had sume structure as rest of kidney. Pancreas had been so compressed that it was a mere string. Spleen, weighed twenty-five ounces; vory dark color and of soft consistency ; the capsule was brittle as inside, which would break like half-pressed curd; there was a spot imbeded in anterior side, size of English hazel-nut, white in color, which to the naked eye looked as if composed of pur, and may have been white infarction. Nothing to be seen about the intestines. The poritoneal fluid was dirty-green, and some increased in amount.

Golwur's Arar. - A surgeon describes in the British Medical Journal, an attack of pain in the shoulder and arm coming on after playing golf, which was confined to the course of the musculo-spiral nerve. There were painful points where the nerve pierced the external intermuscular septum, and numbness and tingling in the dorsum of the thumb and forefinger. He thinks the trouble is due to the bruising of the musculo-spiral nerve by the repeated sudden and Whip-like contractions of the triceps.
STRANGULATED CONGENITAL INGUINAI HERNIA COMPLICATED WITH INFLAMMA'TION OF' THE APPENDIX VERMIFORMIS CON'TAINED IN TIIE SAC.

\author{
\#Y JAMLS H. KNOWLKS, M.D., GLOUCESTKR, MABS.
}

ON 'Tuesday evening, August 7th, Mrs. W. came to my office bringing a poorly nourished child aged three months, suffering from vomiting, hiccough, and in a condition of profound collapse. Respiration was sighing in character, and the child was bathed in profuse perspiration, with clammy skin, eyes staring and pupils widely dilated.

On examination of the abdomen a swelling was seen in the right inguinal region, and the scrotum was dis. tended with a tumor the size of a sunatl orange. Taxis was gently applied, but was unavailing in reducing the size of the tumor. 'The inguinal region and scrotum were scrubbed, and an incision one inch and a half long was made over the long axis of the tumor from above dowuwards, dissecting carefully until the sac was exposed. The sac presenting in the wound was opened, and a gush of stinking pus followed. Through the opening was seen a coil of intestine, dark, congested, thickened, roughened, and giving a boggy sensation to touch. At the same time there also appeared the appendix, two and a half inches long, deeply congested, thickened and infiltrated, with mesentery attuched, but showing no points of sloughing. Numbers of adhesions between the appendix and intestine were seen, but were easily broken up by manipulation. By continued taxis at this stage the appendix could be replaced, but it was impossible to restore the intestinal hernia to the abdominal cavity. On following the intestine down to the site of the stricture, it was found that the adhesions were the principal cause of the difliculty in the reduction of the gut. 'The hernia knife, carefully guarded, was inserted, and the stricture divided, when on breaking up the adhesions the bowel was easily returned to its proper site, nfter thorough flushing with corrosive sublimate $(1-5,000)$ followed by boiled water. Previous to the opening of the sac, the external wound was enlarged, there being so much swelling of the parts involved, and the very small size of the patient not admitting of the necessary manipulations.

Owing to the depth of the wound and the condition of profound collapse, the necessary stitches for the closure of the external opening of the canal could not be taken, but the wound was thoroughly packed with iodoform gauze, and a compress applied over the external abdominal ring, thus retaining the gut. Then retaining stitches were taken, an opening for drainage being left at the lower angle of the incision, the dressing being held in place by a spica bandage of the hip and groin. At the time the condition of the patient was very critical; accordingly external heat was applied, and whiskey given hypodermatically, causing considerable inprovement in the circulation. There was little bleeding during the operation, two small vessels only requiring ligatiou.

The question arose at the time of the reduction of the hernia as to the advisability of amputating the appendix ; but its appearance (there being no sloughing points) and the critical condition of the little patient seomed to justify us in restoring it intact. It was as large as an ordinary lead-pencil, and seemed quite distended previous to severing the constricting band. 
After the pressure was taken off at the point of stricture, the circulation in the appendix improved and it became markedly paler. All of the above-mentioned phenomena prompted to non-interference.

Chloroform was the anesthetic used on account of its convenience in reference to lighting the room and less liability to cuuse vomiting.

The next morning vomiting had ceased, the patient had reacted; the color of the skin was better, and the equilibrium of the circulation was restored, from which time the patient continued to improve.

On the third day following the operation the wound was dressed and the gauze packing removed, when the gut was found in the opening quite restored in color. At this dressing the bowel was replaced, and a compress applied which held it in place.

On the day following the first dressing it was again inspected, and the condition of the external parts was much more satisfactory, being greatly reduced in size. The scrotum had retracted, and the compress was found to hold the bowel in the abdominal cavity.

The wound was allowed to heal by granulation, filling up frow the bottom; and at this writing, three weeks after operution, the external wound is entirely healed, and all of the functions of the bowel are normal.

'The surroundings of the patient were most unfavorable, the operation being done in the kitchen of a small tenewent-house. As near as could be at half an hour's notice, all antiseptic precautions were taken.

In concluding this brief sketch of the case I have to thank Dr. J. C. Jones, of Brookline, Mass., for his valuable assistance.

\section{Medical Bragrega.}

\section{RECENT PROGRESS IN PUBLIC HYGIENE.}

BY BAMUEL W. ABвоTт, M.D.

\section{OFFENSIVE TRADES.}

BY far the best treatise upon the subject of trade nuisances yet published was that of Dr. Ballard in the Reports of the Local Government Board of England.

In a recent review ${ }^{1}$ of the same subject, Dr. A. Bostock Hill presents tho following general statement which is worthy of careful consideration, since the increasing density of population in New England and the introduction of new manufacturing processes give frequent opportunity for the intervention of local health authorities in this direction.

"The number of possible trade nuisances is so great, that I should hardly have time to mention them all by name in a single lecture. . . . Their classification is difficult, owing, in many instances, to their complex nature, but one has been etfected by Dr. Ballard, which has at least the merit of being convenient. It is as follows:

"1. The keeping of animuls.

"2. The slaughtering of animals.

" 3. Other branches of industry in which animal matters, or substances of animal origin, are principally dealt with.

$" 4$. Those in which matters of vegetable origin are dealt with.

"5. Those in which matters of mineral origin are dealt with.

"6. Those in which mixed matters - animal, mineral, and vogetable, are dealt with.

1 Leoture before the Sanitary Instituto of Groat Briluin, Ootob er
18 , 1895, Journal of the Sanltary Instlute, vol,
"One question of general interest applies to all of them: How far can such nuisunces be considered injurious to health? This is a question far more complex than it appears on the surface, because of the difficulty of eliminating from the inquiry the influence of other circumstances - some known, some unknown.

"In certain trade processes emanations of an absolutely poisonous nature are given off, and the effects ure clearly shown on those exposed to the poisonous fumes; for example, arsenic, or irritating gases like hydrochloric acid or carbonic acid. 'This, of course applies chiefly to the workers, but in a less degree, to those who live in the neighborhood of works where such substances are used.

"The general effects produced upon those in the neighborhood of works where ordinary eflluvia arise may be said to be nausea, perhaps vomiting, loss of appotite, headache, giddiness, a general depression or weakness, and malaria; and that such conditions are produced in some we have abuudant proof. It must be remembered that the question of interest or otherwise in the works has a very iwportant bearing on the subject; for while undoubted suffering is caused to those who look upon the works as an annoyance, and have no interest in them, the manufacturers themselves often point to the fact that their work-peoplo, who are most intimately associated with the eflluvia, are not in any way inconvenienced.

"In Dr. Ballard's admirable report, he shows first that in all good faich, employers are apt to forget those cases in which men have left their employ when suffering from ill-health, and have either gone to other occupations or to their clubs as chronic invalids. Again, in many instances such precautions are taken that the effluvia arising are far more noticeable at a distance than they are in the works themselves. There is, therefore, but littlo doubt that trade nuisances are in many instances sources of ill-health to many otherwise healthy people exposed to their influence; much more then must they be injurious to weakly people and invalids, who are more eusily affected by conditions teuding to lower the standard of health. 'That such is the case is found to be the result of some years' experience, and we may assume, therefore, that as the result of theory and practice, any causes which tend to make impure, even in a suall degree, the air we breathe, are potent means for lowering the vitulity which it is the aim of sanitary science to maintain.

"One more point in connection with this subject demands a moment's attention, namely, the allegation sometimes made, that some eflluvia arising from works are disinfecting in their character, and thereforo a blessing in disguise. I have heard this statement made in all seriousness in the high courts, in relution to a nuisance arising from the making of charcoal. If, however, we consider for a moment that for these agents to be of any use as disinfectants they must be present in sufficient quantity to exert a deadly infiuence on the contagia, we see that the infinitesimal quantities diffused in the atmosphere can have no effects as disinfectants or germicides, but cau only irritate and damage the health of the higher living organisms exposed to them."

In summing up the methods of preventing nuisance from offensive trades, Dr. Hill groups them as follows:

(1) Solid offensive refuse must be separated from liquid, the solid portions being removed in close, impervious vessels. 